\title{
Estudo da logística de uma clínica de hemodiálise
}

Study of the logistics of a hemodialysis clinic

DOI: $10.5935 / 2447-8539.20190007$

\section{LARISSA GOMES ESPINOSA; NATÁLIA RABELO GONZAGA; ISADORA VIANA VEIGA; KÁTIA GOMES PEIXOTO; THIZIANE DE OLIVEIRA PALÁCIO; RUBENS MATOS MAIA; ISABELLA GUERRA ARAÚJO; HERBERT CRISTIAN DE SOUZA}

e-mail: larissaespi@hotmail.com

\section{Resumo}

Este estudo de caso objetivou levantar dados sobre o funcionamento e organização logística de uma clínica de hemodiálise na cidade de Araguari-MG. A coleta de dados ocorreu por meio de observação não participante e entrevistas semiestruturadas realizadas com o gestor e com funcionários da instituição. Trata-se de um setor de alto custo com baixa remuneração, a gestão dos estoques conta com um sistema informatizado e a ponderação do gestor e do sócio majoritário. A clínica atende 115 pacientes por mês, quase a totalidade custeada pelos SUS, que cobre a média de treze sessões por mês para cada paciente, que leva em conta apenas o percentual de manutenção da máquina, banho de diálise e agulha/cateter a usar no procedimento, sendo, do valor total arrecadado mensalmente, $50 \%$ voltado para compra de equipamentos, alimentos e pagamento das despesas locais, 30\% para pagamento salarial dos funcionários; e $20 \%$ de lucro. Melhorias no processo de logística geram maior segurança, efetividade, centralidade no paciente, pontualidade, eficiência e equidade na prestação dos serviços de saúde. Como foi visto na clínica, as características da logística neste serviço trazem grandes desafios, todavia visa o bemestar do paciente.

Palavras-chave: Diálise Renal; Logística; Gestão em Saúde.

\section{Abstract}

The aim of this study is to focus on the raising data of the logistical and organizational functioning of a hemodialysis clinic in the city of Araguari in MG. The information was collected through non-participant observation and semi-structured interviews along with the manager and employees of the institution. It is a high-cost sector with low income. They have a computerized system. Both the manager and the majority partner make the decisions. The clinic serves 115 patients per month who are almost all funded by Unified Health System (SUS), which covers the average of thirteen sessions per month/patient. The financial support is the machines' maintenance percentage, dialysis bath and needle/catheter, and half of it is aimed to buying equipment, food, paying local expenses, $30 \%$ for employee's salary and $20 \%$ profit. The improvements in the logistics process generate greater safety, effectiveness, patient centrality, punctuality, efficiency and equity in the delivery of health services. As observed, the characteristics of the logistics in this service bring great challenges and lead to the patient's well-being.

Keywords: $\quad$ Renal Dialysis. Logistic Models. Health Management. 


\section{INTRODUÇÃO}

A logística interna é responsável pelo gerenciamento do processo interno de abastecimento, armazenamento, transporte e distribuição das mercadorias na organização de uma empresa, tendo por finalidade atender às demandas internas desta (ROCHA et al., 2009).

A logística hospitalar surge em resposta à necessidade de propor estratégias, processos e práticas diárias que se traduzam na melhor utilização dos recursos disponíveis, pressupondo a otimização dos serviços garantindo valor acrescentado para o principal objetivo do cuidado médico, empenhando-se em proporcionar elevada eficácia e eficiência. No entanto, é um processo complexo, exigindo muito cuidado e critério na tomada de decisão. A finalidade maior, portanto, é reduzir custos e acrescentar qualidade aos cuidados (FERNANDES, 2015).

É perceptível que os hospitais precisam estar preparados para cuidar de demandas extremas, e neste sentido se faz necessário haver uma boa estrutura física, acompanhamento sistemático das evoluções tecnológicas e excelente efetividade operacional (ROCHA et al., 2009).

Estes locais atuam sob demandas extremas e crescente pressão para o fornecimento de serviços de alto nível, portanto, necessitando de um planejamento eficiente na gestão de suprimentos, e as atividades de logística se faz cada vez mais útil para responder às necessidades dos pacientes (CARETA, 2011).

Empresas que aderem à logística hospitalar, organizando uma gestão de estoque mais cuidada e assente em previsões melhoram seus resultados em grande proporção (FERNANDES, 2015).

A partir de pesquisas em literaturas de relevância direcionadas à logística hospitalar constatou-se a importância dessa dinâmica no ambiente hospitalar. Esta pesquisa se justifica em razão da crescente procura por esses serviços, tornado necessário que tais instituições estejam preparadas para sistematizar todos os insumos disponíveis, objetivando servir seus clientes de maneira efetiva e eficaz.

Frente ao exposto, o presente estudo visou compreender o processo de logística de uma clínica de hemodiálise no município de Araguari - MG.

\section{METODOLOGIA}

O presente trabalho foi realizado em uma clínica de hemodiálise na cidade de Araguari - MG. Como forma de preservar a identidade da instituição, os autores optaram por utilizar o nome "Clínica A". Trata-se de uma organização privada voltada a atendimento de pacientes com insuficiência renal em terapia de diálise. Essa instituição foi escolhida devido à disponibilidade e ao interesse do gestor do local em compartilhar e explorar as dificuldades e potencialidades do seu departamento.

Para a realização da pesquisa, a coleta de dados ocorreu por meio de observação e entrevista semiestruturada realizada com o gestor da instituição. Foi realizada uma visita durante o mês de abril de 2018 com o objetivo de levantar dados gerais sobre o funcionamento da clínica e da organização do setor de logística, onde foi apresentado os macro e micro processos sobre logística.

As perguntas tiveram um enfoque nos processos logísticos do setor (compras, estoques e movimentação de equipamentos). A entrevista foi registrada por meio de anotações realizadas por um dos pesquisadores, e de acordo com os princípios éticos, após compactuação dos envolvidos no preenchimento do Termo de Consentimento Livre e Esclarecido (TCLE).

\section{ESTUDO DE CASO}

A logística de materiais assume importância crescente nas entidades de saúde. Pode-se dizer que a gestão adequada de materiais afasta dos estabelecimentos de saúde três problemas: a compra cara, o estoque excessivo e a falta de materiais. A administração de materiais na área da saúde é mais complexa do que a de outros segmentos da economia, pois o material clínico é muito variável, tem prazos de validade curtos, requer condições ótimas para correta conservação e devem ser passiveis de rastreabilidade (FERNANDES, 2015).

A empresa a que o estudo diz respeito trabalha com um setor da saúde de alto custo com baixa remuneração, que visa em sua totalidade o auxílio ao paciente. Com relação à estrutura, a clínica estudada conta com os espaços: recepção, duas salas de consultórios, sala de recuperação (com equipamentos de emergência), sala de administração, sala de utilidades, duas salas para realização de hemodiálise (onde também ficam guardados a maioria dos materiais utilizados), sala de reprocessamento (para limpeza dos componentes que são reutilizados na hemodiálise - linha e capilar), almoxarifado, e sala de osmose reversa (reprocessamento da água para que esta esteja 100\% limpa para seu uso na hemodiálise).

A qualidade e segurança dos serviços são monitorizadas de forma intensiva segundo rígidas e criteriosas diretrizes. Sendo o doente o elemento central de todo o processo, há uma preocupação no sentido de dar uma resposta integrada à sua insuficiência renal, desde os acessos vasculares, a hemodiálise, medicação adjuvante, nutrição e análises clínicas. De modo a 
oferecer esse olhar holístico ao paciente, a clínica funciona de segunda-feira a sábado das 7:00 da manhã às 22:00 da noite em três turnos, e, conta com uma equipe de funcionários composta de três secretárias, uma nutricionista, um psicólogo, uma assistente social, quatro médicos, três enfermeiras, 15 a 20 técnicas de enfermagem, duas funcionárias da copa, um gestor de estoques e um profissional de serviços gerais.

A clínica apresenta um sistema que centraliza a gestão e aprovisionamento de materiais e consumíveis na própria. A elaboração do planejamento e controle de fluxo e estocagem de produtos é administrada pelo gestor de estoques, que conta com o auxílio Nefrodata ${ }^{\circledR}$, um software de controle gerencial, sendo atualizado pelas enfermeiras e técnicas a cada vez que retiram um material para uso. O Nefrodata ${ }^{\circledR}$ alerta quando há algum produto em baixa, assim o gestor tem o conhecimento da quantidade de cada produto ainda há em estoque, de modo que saiba quando deve adquirir novos materiais.

O gestor é responsável pela seleção de fornecedores, aquisição de novos produtos e gestão de encomendas, mediante aprovação do sócio majoritário da clínica estudada. De acordo com Medeiros e colaboradores (2009), compreende-se que a importância dos estoques na saúde é dimensionada não somente pelo seu valor monetário, mas também pela essencialidade à prestação de serviços a que dão suporte; logo, nesses estoques, não deve haver excessos de materiais (o que implica alto custo), nem a falta deles (com a possibilidade de ocasionar até o óbito de pacientes).

A clínica em estudo atende atualmente a 115 pacientes por mês, sendo a quase totalidade custeados pelos SUS, o qual paga por cada paciente um valor entre RS $1.800,00$ e R\$2.200,00, valor esse que cobre a média de treze sessões por mês para cada paciente, que leva em conta apenas o percentual de manutenção da máquina, banho de diálise e agulha/cateter a usar no procedimento. O custeamento de luvas, máscaras, toucas, algodão, álcool, gaze, materiais utilizados para limpeza/reprocessamento do capilar e das linhas, cobertores e alimentos oferecidos e/ou utilizados com os pacientes é feito pela clínica.

Além dos materiais utilizados já citados, os mais importantes, além da máquina de hemodiálise, são o capilar e as linhas, os quais juntamente com banho de diálise são essenciais para o boa filtração sanguínea. 0 capilar é um tubo composto de 2 partes, parte externa e parte interna com as fibras e espaço para o banho de diálise, que é uma solução combinada de água + ácido + base que retira a ureia do sangue, deixando-o limpo para ser retornado ao organismo do paciente. 0 capilar e as linhas são reutilizáveis; o capilar pode ser utilizado de 40 a 70 vezes, sendo descartado quando atinge menos de $20 \%$ do seu prime inicial (160), e juntamente com ele as linhas. Para ser reutilizado, o capilar e as linhas passam pelo reprocessamento, que é a lavagem, feita por mangueiras de pressão e máquinas com água e ácido peracético (proxitan). Após essa lavagem, sempre é feito um teste de proxitan para testar se há algum resíduo do ácido, pois ele é nocivo/prejudicial à saúde e pode levar o paciente a um choque anafilático.

Os pacientes com insuficiência renal em hemodiálise costumam ficar no instituto por aproximadamente 10 anos. A hemodiálise é importante pois prolonga a vida do enfermo, o prognóstico é de 15 a 20 anos. A diálise é uma técnica que substitui de forma parcial algumas das funções do rim e, à exceção da transplantação renal, não existe nenhuma alternativa para atingir os mesmos fins. É o tratamento definitivo para os que em virtude das suas caraterísticas individuais, não possam ser submetidos a transplantação renal; é o tratamento temporário para os que aguardam transplantação renal (FERNANDES, 2015).

Por fim, assimila-se que todo o trabalho do gestor, baseado no controle da qualidade, visa à satisfação das pessoas, seus colaboradores internos e externos, por isso se faz necessário que possa envolver a todos, colaboradores, unidade, departamento, a medir resultados do seu trabalho, para avaliar se os produtos e serviços atendem às necessidades e expectativas dos clientes.

Desta forma, o paciente é um forte indicador de qualidade e produtividade, pois é ele quem demonstra a satisfação de suas necessidades, sendo a maior delas a preservação e manutenção de sua saúde, através de prestação de serviços médicos, laboratoriais, nutrição, limpeza e higiene e demais setores do hospital que expressem confiabilidade e garantia de qualidade dos produtos e serviços ofertados. Logo, a logística é uma área que contribui para melhor coordenação de funções dentro das organizações, incluindo as unidades hospitalares, permitindo racionalizar custos sem detrimento de suas atividades, apresentando benefícios tanto para a administração e gestão, quanto aos responsáveis pela prestação dos serviços, sobretudo ao cliente.

\section{CONSIDERAÇÕES FINAIS}

Com as modificações sofridas pelos serviços de saúde nos últimos anos, o desempenho das atividades de logística, como aquisição, movimentação e distribuição de suprimentos e equipamentos passou a ser grande influenciador da qualidade dos serviços prestados e da satisfação dos pacientes, sejam nos serviços públicos ou privados.

Portanto, melhorias no processo geram maior segurança, efetividade, centralidade no paciente, pontualidade, eficiência e equidade na prestação dos serviços de saúde. 
As características da logística neste serviço trazem grandes desafios no que tange o desenvolvimento de modelos e métodos que levem em conta a alta complexidade e diversidade de suas atuações no contexto da saúde pública ou privada.

Assim, a logística em serviços de saúde baseia-se na individualidade da situação clínica de cada paciente, visando atender a cada um dentro de suas verdadeiras

\section{REFERÊNCIAS}

CARETA, C.B.; BARBOSA, D.H.; MUSETTI, M.A. Logística hospitalar: proposta e modelagem de atividades do processo de atendimento ambulatorial. Anais do Encontro Nacional de Engenharia de Produção, Belo Horizonte, MG, Brasil, v. 31, 2011. Disponível em:

<http://www.abepro.org.br/biblioteca/enegep2011_TN_STO _135_857_18234.pdf>.Acesso em: 23 mar. 2018.

FERNANDES, L.A. Análise dos fluxos e stocks num serviço de hemodiálise. 2015. Disponível em: <https://repositorioaberto.up.pt/bitstream/10216/79974/2/36229.pdf>. Acesso em: 23 mar. 2018. necessidades de forma eficiente, como foi visto na clínica de hemodiálise estudada, que visa, em primeiro lugar, o bem-estar do paciente, e para isso, executa toda uma forma de gestão específica relacionada à equipamentos, materiais, funcionários, processo de hemodiálise e atendimento público e privado para garantir o atendimento holístico e eficaz.

ROCHA DE MEDEIROS, S.E.; et al. Logística hospitalar: um estudo sobre as atividades do setor de almoxarifado em hospital púbico. Rev. de Adm. da Universidade Federal de Santa Maria, v. 2, n. 1, 2009. Disponível em: <https://periodicos.ufsm.br/reaufsm/article/view/1278>. Acesso em: 23 mar. 2018.

MEDEIROS, S. E. R. DE et al. Logística hospitalar: um estudo sobre as atividades do setor de almoxarifado em hospital púbico [Hospital Logistics: A Study on the Sector Warehouse Activities in Public Hospital]. Revista de Administração da UFSM, v. 2, n. 1, p. 59-79, 2009. 